\title{
Crowdfunding in urology: Canadian perspective
}

\author{
Alessia Di Carlo'; Michael Leveridge²; Thomas B. McGregor ${ }^{2}$ \\ ${ }^{1}$ School of Medicine, Faculty of Health Sciences, Queen's University, Kingston, ON, Canada; ${ }^{2}$ Department of \\ Urology, Queen's University, Kingston, ON, Canada
}

Cite as: DiCarlo A, Leveridge M, McGregor TB. Crowdfunding in urology: Canadian perspective. Can Urol Assoc J 2020 August 7; Epub ahead of print. http://dx.doi.org/10.5489/cuaj.6572

Published online August 7, 2020

$* * *$

\begin{abstract}
Introduction: Crowdfunding is becoming an increasingly used resource for patients to cover costs related to medical care. These costs can be related directly to treatments or indirectly to loss of income or travel-related costs. Little is known as to the extent of which crowdfunding is used for urological disease here in Canada. This study offers a first look at the prevalence of crowdfunding for urological disease and the factors surrounding its use.
\end{abstract}

Methods: In January 2020, we queried the GoFundMe internal search engine for fundraising campaigns regarding urological ailments. Results were categorized according to the major organs of urological disease.

Results: Crowdfunding campaigns are very prevalent within several areas of urology. Prostate cancer and chronic kidney disease represent the most frequent reason for campaigns. Fundraising goals and actual funds raised for malignant disease were significantly more than for benign disease. Interestingly, there was a significant portion of crowdfunding campaigns to cover costs for non-conventional treatments and transplant tourism.

Conclusion: Crowdfunding use to help cover direct and indirect costs of medical care is becoming increasingly apparent through several facets of medicine. This study shows that this statement holds true when looking at patients with urological disease in Canada. As urologists, we need to be aware of this trend, as it highlights the often-unforeseen financial burdens experienced by our patients. 


\section{Introduction}

Crowdfunding has become a common entity in today's society. It refers to online platforms that allow for funding of projects or ventures by a large number of people. ${ }^{1}$ Originally designed to help start-up companies get off the ground, crowdfunding has also began to play a prevalent role in the field of medicine. ${ }^{2}$ This has become increasingly apparent in a number of recent publications looking at its utilization for various aspects of health care..$^{3-6}$

With the cost of health care on the rise, the number of medications and treatments that are not covered by conventional insurance plans is increasing. ${ }^{7-8}$ This is especially apparent in the United States where public health insurance is limited and hence patients are often faced with the ominous task of finding funds to cover basic medical needs. ${ }^{9-10}$ In a public system such as Canada the financial strain is less apparent although patient out-of-pocket expense may be evolving with an increasing number of off-label medications and procedures coming onto market. ${ }^{11}$

It is for this reason that many patients are turning to crowdfunding platforms to help bridge this gap in funding. However, there are also many non-medical costs that patients and families incur when dealing with illness. These include loss of income, cost of travel for care, and equipment such as wheelchairs and medical devices needed for rehabilitation. $^{5}$

Patients with urologic disease and illness are not exempt from these financial burdens. The number of 'off label' treatments in the realm of prostate and kidney cancer has grown immensely over the years. ${ }^{12-14}$ Also, with centralization of certain procedures, including robotics, many patients have to travel and stay close to academic centres from their surgery or treatment. ${ }^{15}$ These unforeseen financial burdens are often daunting for patients and their families and can magnify the stress of dealing with illness.

Little is known as to the extent of which crowdfunding is utilized for urologic disease here in Canada. This study offers a first look at the prevalence of crowdfunding for urologic disease and the factors surrounding its utilization. We also look to better define which disease processes and patient populations turn to crowdfunding and also identify variables that might help predict a successful campaign. In doing so, the study may help identify areas of financial strain for patients and potentially elucidate reimbursement gaps in our health care system.

\section{Methods}

In January 2020 we queried the GoFundMe internal search engine for fundraising campaigns regarding urologic ailments. Results were categorized according to the major organs of urologic disease: prostate, bladder, kidney and testicle. Search terms for campaigns used a key organ followed by the word "Canada." The first 150 campaigns for 
each organ that resulted from the search were analyzed. Search results were further subcategorized into malignant and benign diagnosis and predefined variables of each campaign were recorded.

Search results were cross-examined and all duplicate and non-urologic campaigns were eliminated. Approval by research ethics board was deemed unnecessary seeing as all information gathered was available to the general public.

\section{Results}

\section{Fundraising goals and outreach}

The average fundraising goals of all the urological campaigns analyzed was \$24,476 and the average amount raised in total was $\$ 8,892$. Testicular campaigns possessed the highest average fundraising goal of all conditions (testis: $\$ 46,719$; prostate: $\$ 16,516$; bladder $\$ 12,067$; kidney: $\$ 22,964)$. Additionally, testicular campaigns raised the greatest amount of money on average (testis: $\$ 17,637$; prostate: $\$ 3,548$; bladder: $\$ 5,598$; kidney: $\$ 8,786)$. There were more donors on average for testicular campaigns (testis: 116 ; prostate: 31 ; bladder: 50; kidney: 58). In addition, testicular campaigns also had a higher average number of shares (testis: 544; prostate: 155; bladder: 238; kidney: 361).

When looking at disease process cancer campaigns had higher averages for their fundraising goal in comparison to benign campaigns (cancer: $\$ 34,862$; benign: $\$ 6,109$ ). Cancer campaigns were also able to raise more money on average (cancer: $\$ 19,797$; benign: \$2,045). Cancer campaigns also had more donors compared to benign campaigns (cancer: 99; benign: 17) as well as more shares (cancer: 548; benign: 92).

\section{Campaign recipients and organizers}

The most common type of recipient overall was human $(71 \%)$ followed by charitable organization (29\%). Prostate disease had the highest proportion of charitable organizations as recipients $(60 \%)$, which were mainly 'Movember' campaigns.

The majority of campaigns were organized by a friend or family member (prostate: $31 \%$; testis: 78\%; bladder: 87\%; kidney: 72\%). Prostate campaigns had the largest proportion of self-initiated campaigns (prostate: $60 \%$; testis: $22 \%$; bladder: $13 \%$; kidney: 28\%).

\section{Campaign descriptors and content}

Testis campaigns had the highest word count on average compared to the other campaigns (testis: 679; prostate: 306; bladder: 489, kidney: 431). Cancer campaigns used more words in comparison to benign (cancer: 509; benign: 306).

In regards to key words, many campaigns commented on the recipient's role within their family including identifying the recipient as a parent (prostate: $29 \%$; testis: $22 \%$; bladder: $27 \%$, kidney: $43 \%$ ) or other family member (ex. brother, daughter, 
grandfather) (prostate: $21 \%$; testis: $56 \%$; bladder: 20\%; kidney: 26\%). Another common key phrase identified was the description of the recipient as a "good person" (prostate: 14\%; testis: $44 \%$; bladder: $40 \%$; kidney: $25 \%$ ).

The profile photo was most often a non-medical photo of the recipient (prostate: $52 \%$, testis: $44 \%$, bladder: $67 \%$, kidney: $40 \%$ ) and rarely was the photo of the recipient medical in nature (prostate: $0 \%$; testis: $11 \%$; bladder: $7 \%$; kidney: $11 \%$ ). Photos of the recipient with family were also used (prostate: $14 \%$; testis: 33\%; bladder: $20 \%$; kidney: $32 \%)$. Profile pictures also consisted of other images, such as advertisements for organizations or cartoons (prostate: 33\%; testis: $11 \%$; bladder: 7\%; kidney: $17 \%$ ).

\section{Purpose of campaign}

Explanations for the expenditure and breakdown of expenses was provided in some campaigns (prostate: $24 \%$; testis: $22 \%$; bladder: $27 \%$; kidney: $32 \%$ ).

The primary purposes for bladder and kidney campaigns were to raise funds for treatment, whereas the primary purpose for prostate campaigns was often to raise money on behalf of a charity/fundraiser. A smaller proportion of financial requests were for loss of income, travel/accommodations, food and hospital parking (table 1).

Some campaigns requested funding to help cover non-conventional treatments; this was especially apparent for prostate, testicular and bladder (prostate: $23 \%$; testis: $50 \%$; bladder: 19\%; kidney: 16\%). Kidney campaigns often sought funds to support obtaining an organ via transplant tourism (19\%).

\section{Discussion}

This is among the first studies to look at utilization of crowdfunding within the field of Urology. Similar to the trend in other fields of medicine this study shows that crowdfunding has become a common support for patients dealing with urologic disease. This trend will likely continue to increase in the future as constricted health care budgets may continue to place more direct and indirect costs into the hands of patients.

Many of the campaigns in our study were performed in support of charitable organizations; this was especially apparent in prostate and testicular campaigns where Movember and Prostate Cancer Canada were the charities of choice. The main charity advocated for in kidney campaigns was the Kidney Foundation of Canada, and bladder campaigns only mentioned one charity initiative. This finding is not surprising given the extent of social media use and the fact that most crowdfunding sites are built around sharing campaigns via social media platforms. For charitable organizations this allows maximal exposure to individuals to raise funds.

Given that Canada has a universal health care system that covers most essential treatments for Canadian citizens, the authors originally hypothesized that most crowdfunding campaigns would be to cover non-medical costs such as LOI and travel for 
treatment. We were surprised to see that the majority of campaigns were to cover costs for obtaining treatment, of which a large proportion of these were for nonconventional and alternative medicine.

Geographically, nine out of ten provinces were represented in our study, with the only outlier being Prince Edward Island. The majority of campaigns originated in Ontario, British Columbia and Alberta (37\%, 18\%, 18\%, respectively). Quebec, which is the second most populous province in Canada, only represented $4 \%$ of campaigns, which is likely a result of most crowdfunding sites being offered solely in the English language. These findings are very similar to the geographic distribution found in a recent publication looking at use of crowdfunding for Chronic Kidney Disease (CKD) in Canada. $^{4}$

When broken down by malignant vs. benign disease there is a fairly even split overall between the two, $56 \%$ and $42 \%$ respectively. However when broken down further by disease site, Prostate and Kidney make up the majority of the campaigns, with prostate campaigns being driven mainly by cancer, where as kidney campaigns are driven by benign disease (ESRD, and transplant). This finding is not surprising given the high incidence of these disease processes in Canada and the significant costs associated with each. $^{16-17}$

Similar to other studies, the most common requested contribution by most campaigns was financial to help pay for treatments, travel or loss of income. The funding goals and amounts raised in our study seem consistent when compared to findings or other recent studies. Loeb at al. found that the average goal and actual amounts raised for prostate cancer in the US where $\$ 16,274$ and $\$ 1449$ respectively, compared to our findings of $\$ 15,920$ and $\$ 3548$ here in Canada. Similarly, Pol et. al found that the average amount raised for kidney campaigns to be $\$ 3724$, compared to our finding of $\$ 4878$.

Our study does have limitations. This study is a descriptive look at the utilization of crowdfunding by patients with urological disease within the Canadian system. Despite our interesting findings we did not look at predictors of successful campaigns or funds raised, although this would be a plausible goal for future studies. Furthermore, we did not look into the discernible ethical concerns that arise regarding why patients need to raise funds for treatment within a universal health care system, why certain diagnoses are worthy of more support than others, and how the collected funds are actually expended. Although touched upon by other recent studies we have not delved into these disquiets.

\section{Conclusions}

Crowdfunding utilization to help cover direct and indirect costs of medical care is becoming increasingly apparent through several facets of medicine. This study shows that this statement holds true when looking at patients with urologic disease here in Canada. 
As urologists we need to be aware of this trend as it highlights the often-unforeseen financial burdens experienced by our patients. Furthermore our findings may help outline some funding deficiencies for urologic disease within the Canadian healthcare system and potential opportunities for improvement. 


\section{References}

1. Vox, F., Folkers, K. M., Turi, A., \& Caplan, A. L. (2018). Medical Crowdfunding for Scientifically Unsupported or Potentially Dangerous Treatments. Jama, 320(16), 1705. doi: 10.1001/jama.2018.10264

2. Young, M. J., \& Scheinberg, E. (2017). The Rise of Crowdfunding for Medical Care. Jama, 317(16), 1623. doi: 10.1001/jama.2017.3078

3. Loeb S., Taneja, S., Walter, D., Zweifach, S., \& Byrne, N. (2018). Crowdfunding for prostate cancer and breast cancer. BJU International, 122(5), 723-725. doi: 10.1111/bju. 14408

4. Pol, S. J., Snyder, J., \& Anthony, S. J. (2019). "Tremendous financial burden": Crowdfunding for organ transplantation costs in Canada. Plos One, 14(12). doi: 10.1371/journal.pone.0226686

5. Snyder, J., Crooks, V. A., Mathers, A., \& Chow-White, P. (2017). Appealing to the crowd: ethical justifications in Canadian medical crowdfunding campaigns. Journal of Medical Ethics, 43(6), 364-367. doi: 10.1136/medethics2016-103933

6. Durand, W. M., Johnson, J. R., Eltorai, A. E. M., \& Daniels, A. H. (2017). Medical Crowdfunding for Patients Undergoing Orthopedic Surgery. Orthopedics, 41(1). doi: 10.3928/01477447-20171114-04

7. Law, M. R., Daw, J. R., Cheng, L., \& Morgan, S. G. (2013). Growth in private payments for health care by Canadian households. Health Policy, 110(2-3), 141146. doi: 10.1016/j.healthpol.2013.01.014

8. Lukk, M., Schneiderhan, E., \& Soares, J. (2018). Worthy? Crowdfunding the Canadian Health Care and Education Sectors. Canadian Review of Sociology/Revue Canadienne De Sociologie, 55(3), 404-424. doi: 10.1111/cars. 12210

9. Ridic, G., Gleason, S., \& Ridic, O. (2012). Comparisons of Health Care Systems in the United States, Germany and Canada. Materia Socio Medica, 24(2), 112. doi: $10.5455 / \mathrm{msm} .2012 .24 .112-120$

10. Galvani, A. P., Parpia, A. S., Foster, E. M., Singer, B. H., \& Fitzpatrick, M. C. (2020). Improving the prognosis of health care in the USA. The Lancet, 395(10223), 524-533. doi: 10.1016/s0140-6736(19)33019-3

11. Eguale T, Buckeridge DL, Winslade NE, Benedetti A, Hanley JA, Tamblyn R. Drug, Patient, and Physician Characteristics Associated With Off-label Prescribing in Primary Care. Arch Intern Med. 2012;172(10):781-788. doi:10.1001/archinternmed.2012.340

12. Philippou, Y., Hadjipavlou, M., Khan, S., \& Rane, A. (2013). Complementary and alternative medicine (CAM) in prostate and bladder cancer. BJU International, 112(8), 1073-1079. doi: 10.1111/bju.12062

13. Mani, J., Jüngel, E., Bartsch, G., Filmann, N., Nelson, K., Ackermann, H., ... Arslan, I. (2015). Use of complementary and alternative medicine before and after organ removal due to urologic cancer. Patient Preference and Adherence, 1407. doi: $10.2147 /$ ppa.s90061 
14. Guazzoni, G., Nava, L., Lazzeri, M., Cestari, A., Volpe, A., \& Kirkali, Z. (2010). The Motion: Cryotherapy is an Efficient Alternative for Kidney Cancer. European Urology, 57(1), 168-170. doi: 10.1016/j.eururo.2009.10.016

15. Kassouf W, Aprikian A, Black P, et al. Recommendations for the improvement of bladder cancer quality of care in Canada: A consensus document reviewed and endorsed by Bladder Cancer Canada (BCC), Canadian Urologic Oncology Group (CUOG), and Canadian Urological Association (CUA), December 2015. Can Urol Assoc J. 2016;10(1-2):E46-E80. doi:10.5489/cuaj.3583

16. Terner, M., Redding, N., \& Wu, J. (2016). Increasing Rates of Kidney Failure Care in Canada Strains Demand for Kidney Donors. Healthcare Quarterly, 19(3), 10-12. doi: 10.12927/hcq.2016.24864

17. Wile, Colleen, (2011). Kidney failure in Canada. CANNT Journal, 21(2), 11-2. Retrieved from https://proxy.queensu.ca/login?url=https://search-proquestcom.proxy.queensu.ca/docview/871194212? accountid=6180 


\section{Figures and Tables}

\begin{tabular}{|c|c|c|c|c|}
\hline Variable & Prostate & Testis & Bladder & Kidney \\
\hline \multicolumn{5}{|l|}{ Recipient, n (\%) } \\
\hline Human patient & $17(40 \%)$ & $7(78 \%)$ & $15(100 \%)$ & $46(87 \%)$ \\
\hline Organization & $25(60 \%)$ & $2(22 \%)$ & $0(0 \%)$ & $7(13 \%)$ \\
\hline \multicolumn{5}{|c|}{$\begin{array}{l}\text { Who started campaign, } \mathrm{n} \\
(\%)\end{array}$} \\
\hline Self & $25(60 \%)$ & $2(22 \%)$ & $2(13 \%)$ & $15(28 \%)$ \\
\hline Family/friend & $13(31 \%)$ & $7(78 \%)$ & $13(87 \%)$ & $38(72 \%)$ \\
\hline Charity & $4(10 \%)$ & $0(0 \%)$ & $0(0 \%)$ & $0(0 \%)$ \\
\hline \multicolumn{5}{|l|}{ Location, n (\%) } \\
\hline $\mathrm{ON}$ & $17(40 \%)$ & $3(33 \%)$ & $3(20 \%)$ & $21(40 \%)$ \\
\hline $\mathrm{AB}$ & $5(12 \%)$ & $2(22 \%)$ & $3(20 \%)$ & $12(23 \%)$ \\
\hline QC & $2(5 \%)$ & $1(11 \%)$ & $0(0 \%)$ & $2(4 \%)$ \\
\hline $\mathrm{BC}$ & $9(21 \%)$ & $0(0 \%)$ & $4(27 \%)$ & $9(17 \%)$ \\
\hline $\mathrm{MB}$ & $3(7 \%)$ & $1(11 \%)$ & $1(7 \%)$ & $1(2 \%)$ \\
\hline SK & $0(0 \%)$ & $0(0 \%)$ & $0(0 \%)$ & $2(4 \%)$ \\
\hline NS & $3(7 \%)$ & $0(0 \%)$ & $1(7 \%)$ & $1(2 \%)$ \\
\hline NB & $1(2 \%)$ & $0(0 \%)$ & $0(0 \%)$ & $1(2 \%)$ \\
\hline NT & $0(0 \%)$ & $0(0 \%)$ & $1(7 \%)$ & $0(0 \%)$ \\
\hline Not specified & $2(5 \%)$ & $2(22 \%)$ & $2(13 \%)$ & $4(8 \%)$ \\
\hline \multicolumn{5}{|l|}{ Disease process, $\mathrm{n}(\%)$} \\
\hline Benign & $42(100 \%)$ & $9(100 \%)$ & $10(67 \%)$ & $6(11 \%)$ \\
\hline
\end{tabular}




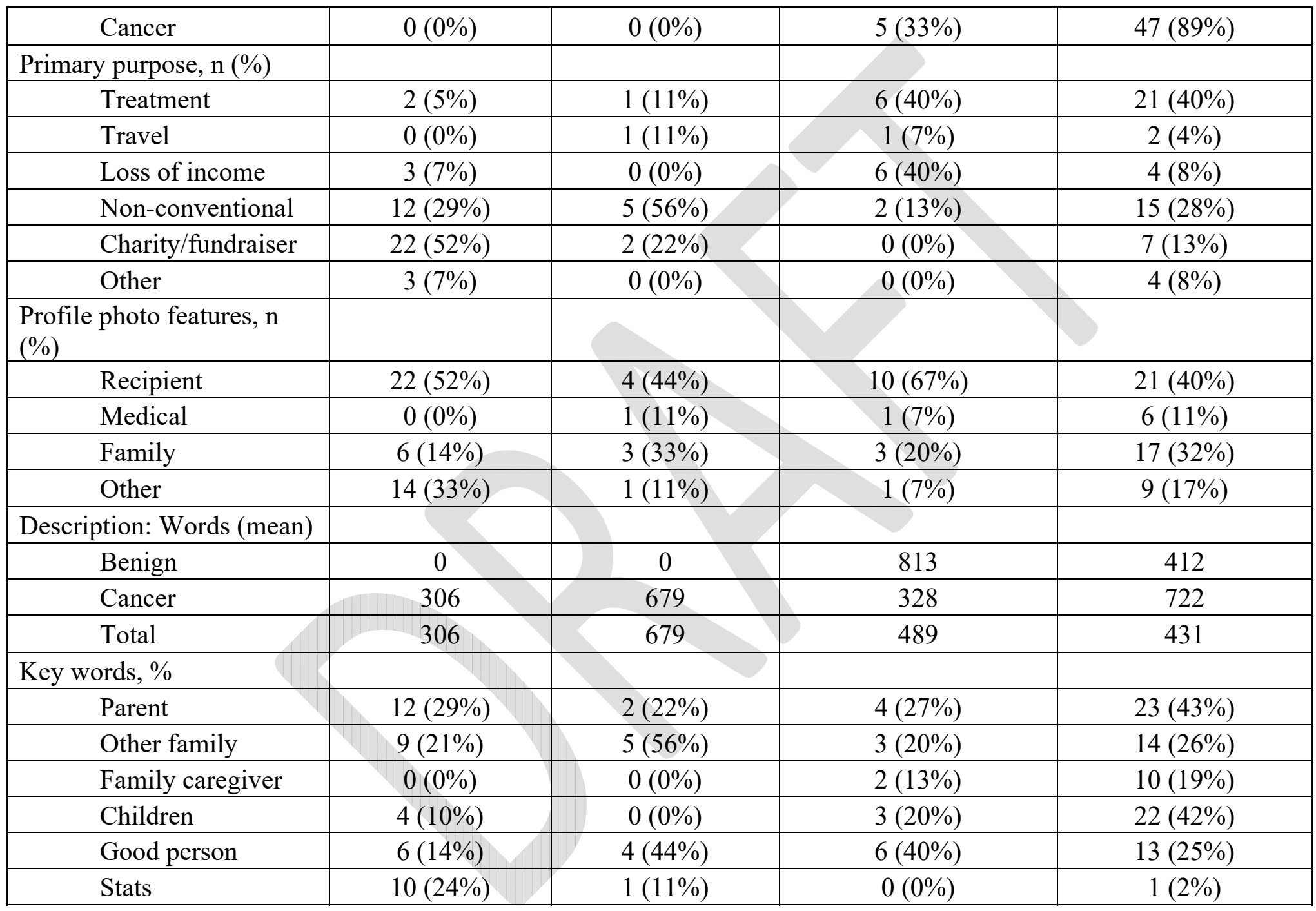




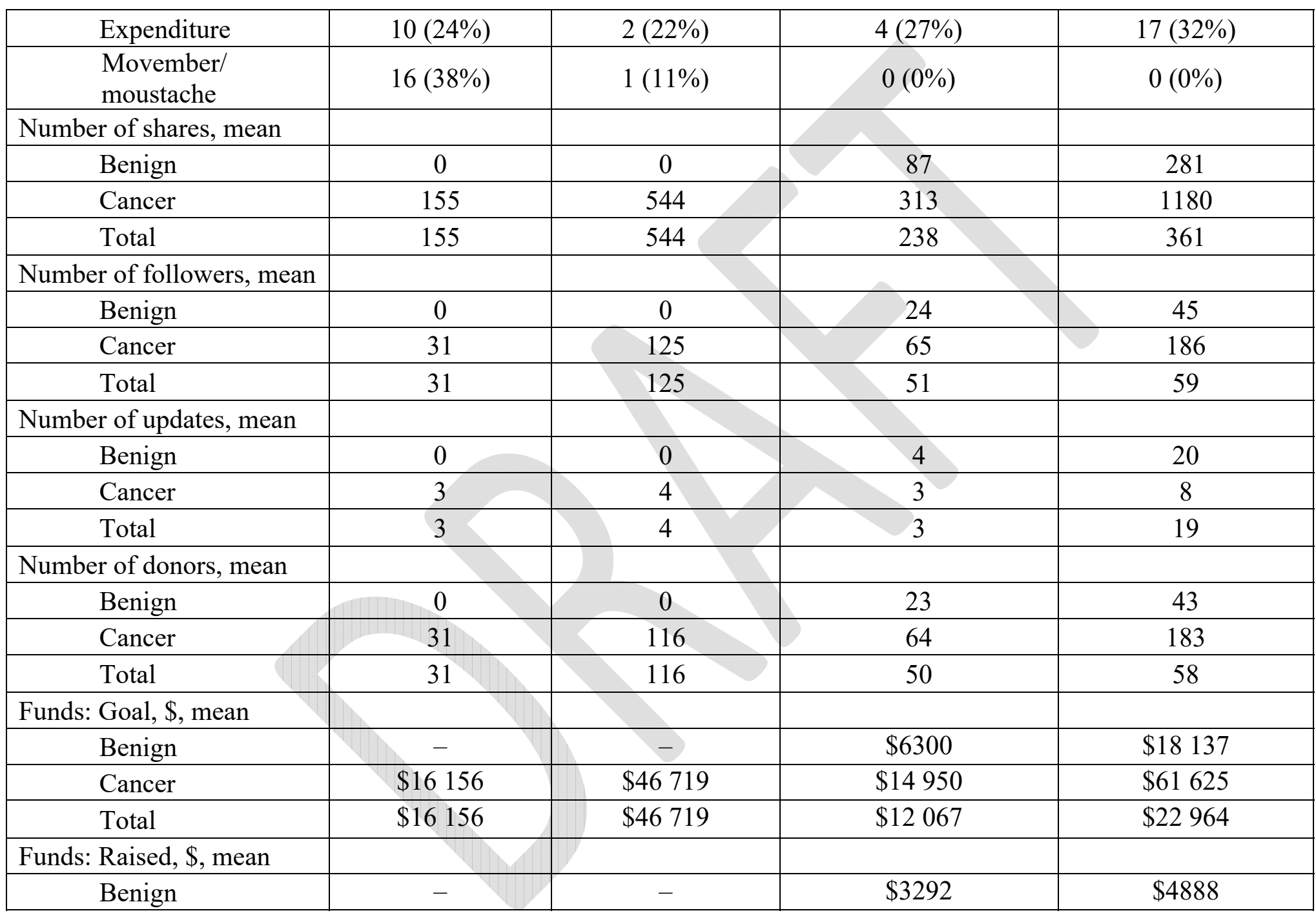




\begin{tabular}{|l|c|c|c|c|}
\hline Cancer & $\$ 3548$ & $\$ 17637$ & $\$ 6752$ & $\$ 51253$ \\
\hline Total & $\$ 3548$ & $\$ 17637$ & $\$ 5598$ & $\$ 8786$ \\
\hline
\end{tabular}




\begin{tabular}{|l|}
\hline Table 2. Non-conventional treatments and alternative therapies \\
\hline Non-conventional treatments \\
\hline RIFE (USA) \\
\hline Phenolic compound from olive oil \\
\hline HIFU \\
\hline Unspecified treatment (Germany) \\
\hline Sheep Sorrel roots \\
\hline Electro cancer therapy with BET-7 device (Germany) \\
\hline Immunotherapy (Canada) \\
\hline DMSO, B17, hyperbaric chamber, chemo at CIPGO clinic (Mexico) \\
\hline CHIPSA therapy (Mexico) \\
\hline Naturopathic medicine (Canada) \\
\hline Holistic treatment (Germany) \\
\hline Immune system management (Canada) \\
\hline Immunity therapy (Mexico) \\
\hline Immunotherapy (opdivo, Yervoy) (U.S.) \\
\hline Foundation one genome screening \\
\hline Unspecified alternative treament (Mexico) \\
\hline Unspecified treatment (Israel) \\
\hline Oxygen therapy chamber \\
\hline Naturopathic medicine and hyperbaric chambers (Canada) \\
\hline Unspecified treatment (U.S.) \\
\hline Transplant (Philippines) \\
\hline Transplant outside of Canada \\
\hline Transplant (Israel) \\
\hline Transplant (India) \\
\hline Transplant (Afghanistan) \\
\hline Transplant (Turkey) \\
\hline Regional chemotherapy (Germany) \\
\hline Holistic treatment (U.S.) \\
\hline Unspecified treatment (Mexico) \\
\hline Transplant (Mexico) \\
\hline
\end{tabular}

